\title{
Brucella abortus: inmunidad, vacunas y estrategias de prevención basadas en ácidos nucleicos ${ }^{\#}$
}

\author{
Brucella abortus: immunity, vaccines and prevention strategies based on nucleic acids \\ R Rivers ${ }^{1}$, E Andrews ${ }^{1}$, A González-Smith ${ }^{1}$, G Donoso ${ }^{1}$, A Oñate ${ }^{1 *}$ \\ ${ }^{1}$ Laboratorio de Inmunología Molecular, Departamento de Microbiología, Facultad de Ciencias Biológicas, \\ Universidad de Concepción, Casilla 160-C, Concepción, Chile.
}

\begin{abstract}
SUMMARY
Brucellosis, a disease caused by the intracellular facultative bacteria Brucella abortus, is a widely distributed zoonosis throughout the world, affecting mainly cattle and causing sterility in males and abortion in pregnant females. Protection against $B$. abortus relies on the activation of cellular immunity involving lymphocytes T CD4 $4^{+}$, subset Th1, secreting gamma-interferon $(\gamma$-INF), a cytokine stimulatings macrophage bactericidal activity and cytotoxic activity of lymphocytes TCD ${ }^{+}$, which are able to lyse Brucella infected cells. The main antigenic components of Brucella are lipopolysaccharide (LPS) and proteins, especially superoxide dismutase (SOD) with demonstrated immune potential. Brucellosis spreading is prevented with vaccines using attenuated or inactivated strains of $B$. abortus, such as strains 19, 45/20 and RB51. On the other hand, several investigators are making efforts to obtain immunity using antigenic structures of Brucella as subcellular vaccines and recently, genetic vaccines based on DNA and RNA molecules. The aim of this review is to give a current overview about brucellosis, its pathogenicity and the clinical syndrome. Firstly, an analysis of the genetic, antigenic and immune characteristics of Brucella is presented. Secondly, the vaccines presently used for prevention and the research on subcellular vaccines are discussed. Finally, the new approach in the vaccine investigation, genetic DNA and RNA vaccines, for Brucella is presented.
\end{abstract}

Palabras clave: Brucella abortus, prevención, vacunas ADN, vacunas ARN.

Key words: Brucella abortus, prevention, DNA vaccines, RNA vaccines.

\section{INTRODUCCION}

La brucelosis es una zoonosis cuya incidencia y prevalencia varían de un país a otro. La infección causada por la especie Brucella abortus es la que más frecuentemente afecta al ganado bovino, causando esterilidad en machos y abortos en hembras preñadas, lo que conduce a graves pérdidas económicas en países en los que es endémica. En países no desarrollados constituye además un problema sanitario para la población humana.

B. abortus es una bacteria Gram negativa con un lipopolisacárido (LPS) fuertemente inmunodominante, el que junto con la capacidad de sobrevivir en el interior de células fagocíticas constituyen sus principales factores de virulencia. La infección en humanos conduce a una enfermedad con tendencia a la cronicidad, con fiebre y malestar recurrentes que deterioran su calidad de vida y que además puede presentar complicaciones como artritis, meningitis, entre otras.

En el ganado bovino la bacteria se ubica en la placenta y órganos reproductores por su afinidad por el eritritol.

Aceptado: 02.08.2005.

\# Proyecto FONDECYT 1010851, Chile.

*Autor para correspondencia e-mail: aonate@udec.cl
La respuesta inmune frente a $B$. abortus, patógeno intracelular facultativo, depende principalmente de la activación de la inmunidad mediada por células, con la participación de células $\mathrm{T} \mathrm{CD}^{+}$de tipo Th1, que secretan interferón gama (INF- $\gamma$ ), citoquina que estimula tanto la actividad bactericida de macrófagos como la actividad citotóxica de los linfocitos $\mathrm{T} \mathrm{CD}^{+}$. Estos últimos son capaces entonces de destruir células infectadas con Brucella.

La identificación de proteínas con demostrada capacidad inmune, entre las que se ha identificado la superóxido dismutasa $\mathrm{Cu} / \mathrm{Zn}$ de $B$. abortus (SOD), ha permitido diseñar estrategias de vacunación basadas en componentes subcelulares, ya que la prevención de la diseminación de la brucelosis, basada en la vacunación con bacterias atenuadas de Brucella abortus cepa 19, cepa RB51 y cepa 45/20, no ofrece garantías de seguridad en su administración, ni tampoco permite la completa erradicación del microorganismo patógeno. En la actualidad las nuevas tendencias en investigación acerca de vacunas se están desarrollando en base a moléculas de ácidos nucleicos, como las vacunas ADN y las vacunas ARN.

1. DISTRIBUCION GEOGRAFICA. La brucelosis tiene una distribución geográfica limitada, siendo un problema 
importante en el Mediterráneo, el oeste de Asia y algunas zonas de Africa y Latinoamérica, especialmente en países con bajos recursos económicos (Corbel 1997, Moreno y Moriyón 2002). En el centro y norte de Europa y en Australia la infección por B. abortus ha sido prácticamente erradicada. En Norteamérica, la brucelosis es especialmente prevalente en las zonas agrícolas del norte y centro de México (Gándara y col 2001), mientras que en Canadá y Estados Unidos ha disminuido considerablemente en los últimos años. B. abortus está presente en todos los países de América Central, siendo la prevalencia de un 4 a un 8\% (Moreno 2002). En Sudamérica se encuentra en varios países, donde en muchos casos es endémica y un problema sanitario importante (Corbel 1997, Lucero y col 1999, Rodríguez y col 2001). En Chile, la Décima Región de Los Lagos es la que comprende la mayor área productora de leche y, además, tiene la mayor concentración de ganado infectado (Ramírez y Sigal 2002, Rivera y col 2002).

2. PATOGENIA. La mayoría de los animales se infectan directamente a través de la mucosa oronasal, por ingestión de alimentos contaminados o por inhalación de polvo de los establos con microorganismos que los animales han secretado con la leche o los exudados vaginales después del aborto (Rodríguez y col 2001). B. abortus, además de infectar al ganado bovino, puede infectar a otras especies como búfalos, bisontes, alces, jabalíes, zorros, renos, camellos y animales marinos (Mandell 1995, Cloeckaert y col 2000). Inmediatamente después de la penetración e independientemente de la vía de entrada, las bacterias son transportadas, libres o en el interior de células fagocíticas, hasta los ganglios linfáticos más próximos al lugar de entrada. Si las bacterias no son destruidas, pueden sobrevivir largos períodos de tiempo en el interior de las células fagocíticas (Ilarmon y col 1988). Los ganglios linfáticos responden a la agresión por medio de una hiperplasia reticuloendotelial y linfática, que puede tardar varias semanas en producirse y persistir durante meses (Rodríguez y col 2001). En los fagosomas de los macrófagos, Brucella sobrevive y se multiplica, inhibiendo la fusión del fagosoma que contiene la bacteria y el lisosoma, mediante la acidificación rápida del medio (Pizarro-Cerda y col 1998, Celli y col 2003, Ko y Splitter 2003). En células fagocíticas no profesionales, la internalización de B. abortus se asocia al dominio extracelular de la proteína tirosina quinasa y la activación de una serie de pequeñas GTPasas (GuzmánBerri y col 2001), tendiendo a localizarse dentro del retículo endoplásmico rugoso (Corbel 1997). En infecciones experimentales, en ratones, se ha observado que la infección tiene dos fases: durante las primeras dos semanas la bacteria se multiplica rápidamente; en la segunda fase, el número de bacterias se estabiliza hacia la quinta o sexta semana y luego decrece lentamente hasta desaparecer (Hong y col 2000). La especial afinidad que estas bacterias tienen por el endometrio grávido y por la placenta fetal de bovinos hace que estas bacterias también proliferen extensamente en trofoblastos de la placenta que rodean al feto (Meador y Deyoe 1989), lo que condiciona que la principal manifestación clínica de la infección aguda en los animales sea el aborto durante el último tercio de la gestación, o el nacimiento de animales prematuros poco viables (Ficht 2003). En bovinos machos provoca alteraciones testiculares y una disminución de la fertilidad, acompañadas algunas veces por abscesos en testículos y epidídimo (Hausler y Koontz 1974).

En humanos la infección se produce a través del contacto con secreciones de animales infectados o consumo de leche cruda o queso contaminado. El consumo de carne no es una fuente de contaminación (Mandell 1995). Brucella puede ingresar al organismo a través de lesiones de la piel, mientras se manipulan animales infectados o sus desechos (Mandell 1995, Sauret y Vilissova 2002). En países en que la infección por Brucella es endémica en la población animal, la infección por Brucella en humanos es frecuente (Roop II y col 1994, Yagupsky 1999), sin embargo, la transmisión persona a persona es extremadamente inusual (Fiori y col 2000). La enfermedad puede ser adquirida por exposición ocupacional de los trabajadores de mataderos, carniceros y veterinarios, al inhalar aerosoles contaminados o en viajes a lugares donde la infección es endémica (Yagupsky 1999). Las infecciones asociadas al trabajo de laboratorio representan el $2 \%$ de los casos y se ha informado que el período de incubación de la brucelosis adquirida por accidente en el laboratorio puede variar entre seis semanas a cinco meses (Fiori y col 2000).

3. GENETICA DE BRUCELLA. El ADN de Brucella contiene un $58-59 \%$ de $\mathrm{G}+\mathrm{C}$ (guanina y citosina) y el tamaño total del genoma se ha estimado en aproximadamente $2,5 \times 10^{6}$ pares de bases (Allardent-Servent y col 1988); este tamaño es menor al de Escherichia coli $\left(4,7 \times 10^{6}\right.$ pares de bases). Dos características genéticas de Brucella llaman especialmente la atención, en primer lugar, la existencia de dos cromosomas circulares en la mayoría de las especies y biotipos, y en segundo lugar, la ausencia de plásmidos. Esta última característica refleja probablemente la adaptación a un nicho ecológico (el ambiente intracelular) estable y sin competencia microbiana, en el que no es necesaria la plasticidad genética que se deriva de los plásmidos y que es propia de ambientes con gran cantidad de microbios (intestino, tierra, etc.). El género Brucella tiene seis especies reconocidas, las que exhiben distintas preferencias por su huésped (Mayer 1964) y muestran más de $94 \%$ de homología en su genoma (Halling y col 2005), lo que apoya la proposición de que las especies clásicas de Brucella son cepas de Brucella melitensis (Verger y col 1995). Sin embargo, se ha encontrado polimorfismo en determinadas secuencias genómicas que coinciden con las especies clásicas e in- 
cluso con las biovariedades. Se estima, además, que el $8 \%$ del genoma de Brucella se destina a funciones necesarias para la sobrevivencia y la virulencia, en comparación al estimado para Salmonella que es sólo el 3-4\% (Hong y col 2000).

\section{INMUNIDAD FRENTE A BRUCELLA}

4.1. Inmunidad natural. En estados tempranos de la infección por Brucella, el rol de la respuesta innata es reducir el número inicial de bacterias promoviendo una respuesta Th1 en el huésped (Ko y Splitter 2003). Los macrófagos, los neutrófilos, las células Natural Killer (NK) y el complemento juegan un rol clave en esta fase temprana de la respuesta a la invasión frente a este microorganismo (Golding y col 2001).

4.1.1. Macrófagos. Los macrófagos juegan un rol central en la respuesta inmune frente a Brucella, ya que actúan como células fagocíticas profesionales y como células presentadoras de antígenos. Procesan antígenos en sus compartimentos intracelulares y los presentan en el contexto del Complejo Mayor de Histocompatibilidad (MHC) a linfocitos $\mathrm{T}$, promoviendo de esta manera la respuesta inmune adaptativa (Forestier y col 2000). En este sentido, se ha encontrado que el LPS de Brucella interfiere con la vía de presentación de antígenos por MHC clase II (Murphy y col 2002). Las funciones bactericidas de los macrófagos frente a Brucella se encuentran centradas en la actividad de las especies reactivas de oxígeno (Oliveira y col 2002) y las especies reactivas de nitrógeno, las cuales son inducidas por IFN- $\gamma$ y el factor de necrosis tumoral alfa (TNF- $\alpha$ ) (Ko y Splitter 2003).

Los receptores Toll-like (TLR) juegan un rol importante en el inicio de la respuesta inmune innata. Estos receptores presentes en células fagocíticas profesionales reconocen productos microbianos uniéndose directamente a ellos e inducen señales intracelulares que activan factores de transcripción (como NF-kB) que modulan la producción de citoquinas. Estos receptores pueden ser activados por diversos productos microbianos; el receptor Toll-like 4 (TLR4) es activado por LPS, el TLR9 por ADN bacteriano, el TLR2 por productos de la pared celular de bacterias Gram positivas y TLR5 por flagelina (Vasselon y Detmers 2002).

4.1.2. Neutrófilos. Los neutrófilos están implicados en el desarrollo de una defensa temprana frente a una infección por Brucella mediante la fagocitosis y posterior destrucción del microorganismo. En primer lugar, los neutrófilos son atraídos al sitio de la infección por estímulos químicos originados o derivados del microorganismo (Wilkinson 1980, Birmingham y col 1982), para posteriormente fagocitar la bacteria, preferentemente opsonizada (Young y col 1985). Una vez que el patógeno es fagocitado, se desarrolla una serie de mecanismos destructivos en el neutrófilo, con el fin de eliminar la bacteria, mediante el aumento del consumo de oxígeno que lleva a la aparición de radical superóxido, peróxido de hidrógeno y otros radicales derivados del oxígeno, junto con la activación de la enzima mieloperoxidasa y la fusión del lisosoma con los fagosomas que contienen la bacteria, liberándose hidrolasa ácida, glicosidasa, proteasa y lipasa. Sin embargo, la bacteria ingerida puede sobrevivir al mecanismo destructivo de los fagocitos (Smith y Fritzgeorge 1964), gracias a moléculas de bajo peso molecular que inhiben el sistema antibacteriano mieloperoxidasa-peróxido de hidrógeno-haluro (Canning y col 1985). Por ello, aunque los neutrófilos son las primeras células relacionadas con la eliminación de patógenos extraños, ellos son considerados de baja eficiencia contra Brucella, ya que esta bacteria puede crecer y sobrevivir en su interior y además es diseminada a través de estos leucocitos a órganos y diferentes localizaciones, desarrollándose una infección persistente.

4.1.3. Células Natural Killer. Las células NK forman parte de la primera línea de defensa contra Brucella y una vez que son activadas pueden eliminar células infectadas. B. abortus puede activar la actividad lítica de las células NK, estimulando la producción de interleuquina12 (IL-12) por parte de las células presentadoras de antígenos. IL-12 además estimula a las células NK a secretar IFN- $\gamma$ (Fernández y col 1995; Golding y col 2001).

4.1.4. Complemento. Uno de los primeros eventos que ocurren después de la entrada de la Brucella al organismo es la activación del complemento por la vía alterna; sin embargo, se ha demostrado que esta vía es incapaz de eliminar la cepa virulenta de Brucella abortus 2308 (Eisenschenk y col 1999). Por lo tanto, la lisis de Brucella estaría mediada principalmente por la vía clásica del complemento, la cual es dependiente de anticuerpos (Fernández y col 2001).

4.2. Inmunidad adaptativa. Está ampliamente aceptado que la inmunidad mediada por células es el mecanismo efector más relevante en la protección frente a Brucella debido a que es un parásito intracelular (Oliveira y col 1996). Las citoquinas son moléculas clave para una adecuada respuesta inmune mediada por células (Oliveira y col., 1996). La exposición prolongada de un animal a Brucella cambiaría la naturaleza de la respuesta inmune, desde una inmunidad mediada por células hacia una respuesta humoral (caracterizada por la producción de IgM e IgG1), respuesta que se relaciona con una disminución en la actividad de las células $\mathrm{T}$ ayudadoras tipo 1 , con una baja en la producción de INF- $\gamma$, favoreciéndose de esta forma un incremento de la actividad de las células $\mathrm{T}$ ayudadoras de tipo 2, disminuyendo la respuesta inmune celular, lo que favorecería de esta forma el establecimiento de la enfermedad crónica (Oñate y col 2000). Las fun- 
ciones de la respuesta inmune adaptativa en la brucelosis se basan principalmente en tres mecanismos. Primero, la producción de IFN- $\gamma$ por células $\mathrm{T} \mathrm{CD}^{+}, \mathrm{CD} 8^{+}$, y células $\mathrm{T} \gamma \delta$, que activa la función bactericida en macrófagos. Segundo, la citotoxicidad de células $\mathrm{T} \mathrm{CD}^{+}$y células T $\gamma \delta$ que eliminan macrófagos infectados. Y tercero, isotipos de anticuerpos Th1, tales como IgG2a que opsonizan al patógeno para facilitar su fagocitosis (Ko y Splitter 2003).

En general, se considera que los anticuerpos bloqueadores no son efectivos en la respuesta inmune contra Brucella (Corbeil y col 1988). Sin embargo, los animales infectados con Brucella producen anticuerpos contra varios componentes bacterianos (Tabatabai y Hennager 1994) que interfieren en la eliminación del patógeno, especialmente aquellos anticuerpos específicos para el antígeno $\mathrm{O}$ y algunas porinas. En este sentido, los anticuerpos serían importantes en bloquear la liberación de cantidades demasiado elevadas de Brucella al medio extracelular.

4.2.1. Linfocitos $T C D 4^{+}$y $C D 8^{+}$. Después de la activación de los macrófagos, las células T inmaduras (Th0) se diferencian de células efectoras y de memoria, que están programadas para secretar distintos patrones de citoquinas (Golding y col 2001). Las células Th1 secretan interleuquina-2 (IL-2) e INF- $\gamma$, mientras que los linfocitos Th2 producen interleuquina-4 (IL-4), interleuquina-5 (IL5) e interleuquina-10 (IL-10) (Zhan y col 1995). La generación de células Th1 de memoria sólo puede realizarse si la respuesta inicial al estímulo se asocia a la producción de IL-12 e IFN- $\gamma$ (Scharf y col 2001).

El rol principal de la secreción de IFN- $\gamma$ por las células Th1 en la inmunidad contra Brucella es activar la función bactericida de los macrófagos y linfocitos $\mathrm{T} \mathrm{CD}^{+}$ citotóxicos, así como la estimulación de la secreción de IgG2a (Scharf y col 2001; Ko y Splitter 2003). En términos numéricos, la población celular predominante es la de linfocitos T CD $4^{+}$productores de IFN- $\gamma$ (Ko y Splitter 2003), responsables de la activación de macrófagos y la atracción de células inflamatorias efectoras, de ahí su importancia en promover la respuesta celular adquirida contra Brucella (Bae y col 2002, Wyckoff 2002). Además, el IFN- $\gamma$ inhibe la acción de IL-4 sobre las células T (Scharf y col 2001).

Las células citotóxicas $\mathrm{T} \mathrm{CD}^{+}$pueden actuar como células efectoras y eliminar macrófagos infectados con Brucella directamente (Oliveira y col 2002; Wyckoff 2002). Las células blanco son reconocidas por las células citotóxicas en el contexto de las moléculas de histocompatibilidad de clase I (MHC I) y son eliminadas por la acción de perforinas y granzimas (Golding y col 2001).

4.2.2. Linfocitos $T \gamma \delta$. Las células $\mathrm{T} \gamma \delta$ representan una pequeña población de linfocitos, con un patrón único de reconocimiento de antígenos (Dieli y col 2003). En humanos, las células $\mathrm{T} \gamma \delta$ controlan el aumento en el número de microorganismos ya que secretan TNF- $\alpha$ e IFN- $\gamma$, después de ser activadas por antígenos no peptídicos, en su mayoría fosfoantígenos, los cuales no son presentados en el contexto del MHC (Giambartolomei y col 2002, Baldwin y col 2002, Ko y Splitter 2003). Mediante la secreción de estas citoquinas, activan la función bactericida de los macrófagos y, además, son capaces de lisar células infectadas por citotoxicidad directa in vitro. El rol de estas células in vivo aún no ha sido determinado (Ko y Splitter 2003), aunque se cree que son parte de la inmunidad innata (Wyckoff 2002). En bovinos menores de un año, la población celular predominante es la de células $\mathrm{T} \gamma \delta$ y no la de células $\mathrm{T} \alpha \beta$, lo que sugiere que el rol de este tipo celular es más significativo en la infección del ganado con brucelosis (Ko y Splitter 2003). De todas maneras, en bovinos, la producción de IFN- $\gamma$ por estas células es menor que la producida por las células $\mathrm{CD}^{+}$(Baldwin y col 2002).

4.2.3. Linfocitos B. Las células B son estimuladas directamente por las células $\mathrm{T}$ a través de la interacción de moléculas coestimulatorias como CD40 y su ligando CD40L presente en la célula $T$, lo cual, junto a las citoquinas liberadas, son importantes en promover el cambio de isotipo de IgM a IgG (Golding y col 2001). Con respecto al rol que cumplirían los anticuerpos durante la infección por Brucella, se ha visto que tanto IgM como $\mathrm{IgG}$, en bajas concentraciones, son capaces de promover la lisis de Brucella a través de la vía clásica del complemento (Corbeil y col 1988). También se han encontrado títulos elevados de IgG anti-SOD Cu/Zn en animales infectados, pero aún no se determina si estos anticuerpos juegan un rol importante en la inmunidad contra Brucella (Tabatabai y Hennager 1994). La opsonización acoplada al aumento de muerte de Brucella intracelular podría ser considerada como el principal rol de los anticuerpos contra la infección con Brucella (Ko y Splitter 2003). Aunque paradójicamente en brucelosis bovina la alta concentración de IgG durante la infección activa previene la lisis extracelular de la bacteria mediada por complemento y promueve la fagocitosis bacteriana, aumentando la localización intracelular de la bacteria y la extensión de la enfermedad (Ko y Splitter 2003).

4.2.4. Citoquinas. Las citoquinas son moléculas clave en el control de la brucelosis, ya que permiten dirigir las respuestas hacia una respuesta inmune celular o humoral. B. abortus estimularía a las células presentadoras de antígenos para que secreten IL-12, la que induce a los linfocitos Th0 a diferenciarse en linfocitos Th1, secretores de IFN- $\gamma$ (Splitter y col 1996, Oliveira y col 2002, Ko y Splitter 2003). Sin embargo, otros autores señalan que Brucella no es un inductor potente de la secreción de IL12 (Pasquali y col 2001). IFN- $\gamma$ participa en la regula- 
ción de los mecanismos defensivos de los macrófagos y es considerado un factor crucial para el desarrollo de la protección contra la infección por Brucella (Oliveira y col 1996).

Interleuquina-18 (IL-18) citoquina sintetizada por macrófagos activados, también estimula la producción de IFN- $\gamma$, por lo que actúa sinérgicamente con IL-12 sobre las células $\mathrm{T}$ en la estimulación de la respuesta mediada por células contra Brucella (Pasquali y col 2002).

TNF- $\alpha$ contribuye a la resistencia frente a Brucella por una vía independiente de IFN- $\gamma$, estimula el influjo de fagocitos al sitio de infección y participa en la activación de los macrófagos (Zhan y col 1996).

IL-10, producida por linfocitos $\mathrm{CD}^{+} \mathrm{Th} 2$, macrófagos activados y algunas poblaciones de células B, inhibe la respuesta Th1, ya que disminuye la capacidad de presentar antígenos de los macrófagos e inhibe la secreción de IFN- $\gamma$, por lo tanto, aumenta la susceptibilidad a la infección por Brucella (Fernández y Baldwin 1995, Giambartolomei y col 2002).

5. ANTIGENOS DE BRUCELLA. Desde un punto de vista antigénico en Brucella existen dos componentes fundamentales: el lipopolisacárido (LPS) y las proteínas (Hinsdill y Berman 1967).

5.1. Lipopolisacárido. El LPS es diferente entre cepas rugosas o lisas de Brucella (Mandell 1995). Se ha descrito que el LPS de cepa lisa, que contiene polisacárido $\mathrm{O}$, probablemente juega un rol importante en la sobrevivencia intracelular, en comparación con una cepa rugosa que no tiene o tiene muy poca cadena $\mathrm{O}$ (Corbell 1997). La falta de una definición genética sobre cepas rugosas naturales, que son patogénicas para su hospedadores, como Brucella ovis y Brucella canis, confunde tal interpretación. Sin embargo, se ha descrito en $B$. ovis y B. canis la presencia de LPS que es idéntico al encontrado en cepas mutantes lps de B. abortus, mutantes que no tienen cadena $\mathrm{O}$, pero tienen diferente capacidad de sobrevivencia dentro de los macrófagos (Allen y col 1998).

La cadena O del LPS es la estructura antigénica más expuesta de esta bacteria, un homopolímero de aproximadamente 100 residuos de 4-formamido-4,6-didesoximanosa (Caroff y col 1984, Corbel 1997, Cloeckaert y col 2002), componente inmunodominante en cepas lisas de B. abortus, provocando que animales infectados produzcan anticuerpos específicos contra este antígeno. Los anticuerpos producidos en ratones son principalmente de isotipos $\operatorname{IgG} 2$ a e $\operatorname{IgG}_{3}$, con baja producción de $\operatorname{IgM}$ (Vemulapalli y col 2000a). Estos anticuerpos representan un componente importante dentro de la inmunidad protectora contra Brucella, complementando la respuesta inmune mediada por células (Montaraz y col 1986).

La avidez del LPS para unirse al receptor CD14 de los fagocitos mononucleares se debe al lípido $\mathrm{A}$; esta interacción estimula en estas células la producción del TNF- $\alpha$, interleuquina-1 (IL-1), interleuquina-6 (IL-6) e interleuquina-8 (IL-8), los cuales son mediadores de la mayoría de los síntomas de choque séptico (Aréstegui y col 2001).

El LPS de Brucella se diferencia en estructura química y actividad biológica al LPS de bacterias enteropatógenas comunes, ya que no está estabilizado por cationes divalentes; contiene una menor carga negativa y menor cantidad de ácido 2-ceto-3-deoxioctanoico que el LPS de otras bacterias, disminuyendo así su susceptibilidad a la acción de péptidos catiónicos bactericidas (Folch y Oñate 1995). Las moléculas de manosa que presenta el extremo terminal del LPS de Brucella (cepa lisa) favorecen la adherencia a los fagocitos mononucleares del huésped, ya que éstos tienen los receptores de manosa (Pontow y col 1992). Además de los fagocitos mononucleares, las células de la placenta contienen gran cantidad de receptores de manosa, lo que sumado al tropismo de estas bacterias por el eritritol placentario de bovino, aumenta las probabilidades de abortos en estos animales, debido a la presencia de la bacteria en ese tejido (Aréstegui y col 2001).

5.2. Proteínas. En estudios sobre componentes estructurales proteicos de relevancia en Brucella se han descrito proteínas de membrana externa, proteínas de ubicación citoplasmática y proteínas de choque térmico.

Las proteínas de membrana externa han sido clasificadas en tres grupos: el Grupo I se relaciona con la biosíntesis de la propia envoltura celular y tienen un peso molecular entre 88 a 94 kDa; el Grupo II es equivalente a las porinas de otras bacterias Gram negativas, como Omp 2, OmpC y OmpF y tienen un peso molecular entre 35 a $40 \mathrm{kDa}$, finalmente, el Grupo III con peso molecular entre 25 a $30 \mathrm{kDa}$ que interacciona fuertemente con el LPS (Verstreate y col 1982, Santos y col 1984, Douglas y col 1984, Verstreate y Winter 1984, Ficht y col 1989). Estos tres grupos de proteínas de membrana externa son reconocidos por el sistema inmune durante el curso de la infección (Bae 1999).

Entre las proteínas citoplasmáticas de importancia destacan la proteína superóxido dismutasa $\mathrm{Cu} / \mathrm{Zn}$ (SOD) y la catalasa. La SOD $\mathrm{Cu} / \mathrm{Zn}$ forma parte del sistema de defensa antioxidante de Brucella, el cual protege a la bacteria de los efectos tóxicos de los intermediarios reactivos del oxígeno, ya que transforma los radicales superóxido $\left(\mathrm{O}_{2}^{-}\right)$en peróxido de hidrógeno $\left(\mathrm{H}_{2} \mathrm{O}_{2}\right)$ y oxígeno gaseoso $\left(\mathrm{O}_{2}\right)$, contribuyendo a la sobrevivencia intracelular de Brucella (Ko y Splitter 2003). La proteína SOD Cu/Zn pertenece a la familia de metaloproteínas, clasificada en tres tipos (SOD Cu/Zn, SOD Mn y SOD Fe) dependiendo del metal que se encuentre en el sitio activo. La enzima catalasa ayuda a la proteína $\mathrm{SOD} \mathrm{Cu} / \mathrm{Zn}$ a detoxificar el ambiente bacteriano, actuando sobre el peróxido de hidrógeno $\left(\mathrm{H}_{2} \mathrm{O}_{2}\right)$ generado al interior del macrófago des- 
pués de la fagocitosis de la bacteria, transformándolo en agua y oxígeno (Aréstegui y col 2001). La expresión de estas enzimas favorecería la permanencia de Brucella en el interior del fagocito.

El rol de las proteínas de choque térmico en la patogénesis de Brucella es incierto. Se ha observado que en bacterias intracelulares se expresan niveles elevados de proteínas de choque térmico en el ambiente intracelular (Roop II y col 1994, Ko y Splitter 2003, Bae y col 2002). Entre estas se encuentran GroEL (60 kDA), GroES (10 $\mathrm{kDa})$ y HtrA $(60 \mathrm{kDa})$. Las proteínas GroEL y GroES son chaperonas relacionadas con el plegamiento correcto de proteínas, mientras que HtrA (High temperature requirement $\mathrm{A}$ stress response protein) es una proteasa que degrada proteínas dañadas oxidativamente (Bae y col 2002). HtrA protege a la bacteria intracelular del daño oxidativo y contribuye a la resistencia de Brucella a la destrucción por los fagocitos (Elzer y col 1996). La enzima UvrA repara las lesiones del ADN después del daño oxidativo, como mecanismo de protección bacteriano (Oliveira y col 1996).

6. VACUNAS CONTRA BRUCELLA ABORTUS. La prevención de la diseminación de la brucelosis se basa en la administración de vacunas adecuadas contra la infección por B. abortus. Con este objetivo se han utilizado clásicamente cepas bacterianas atenuadas y componentes antigénicos propios de la Brucella. La habilidad de un antígeno específico para inducir en forma preferencial una respuesta Th1 es un aspecto importante a considerar en el desarrollo de vacunas contra Brucella abortus (Stevens y col 1994, Oliveira y col 1996).

\subsection{BACTERIAS ATENUADAS}

6.1.1. Brucella abortus S19. La cepa 19 de Brucella abortus es una cepa lisa que posee la cadena O del LPS, por ello, en animales inmunizados con esta cepa se pueden observar anticuerpos específicos contra este antígeno del tipo IgG1, IgG2b e IgM (Vemulapalli y col 2000a). El defecto genético que permite la atenuación de esta cepa aún no ha sido definido, pero hace que pierda un mecanismo de virulencia esencial (Briones y col 2001). Su efectividad en el ganado bovino depende de variables como la edad de vacunación, dosis, ruta de administración y de la prevalencia de la brucelosis en el rebaño vacunado (Schurig y col 2002). Los anticuerpos inducidos por la vacunación con esta cepa interfieren con el diagnóstico tradicional de bovinos infectados con cepas silvestres de B. abortus, por lo que tiene un uso limitado en la vacunación del ganado; esta cepa puede también inducir aborto en hembras preñadas y es patógena para la especie humana (WHO 1997, Oliveira y Splitter 1996, Olsen 2000).

6.1.2. Brucella abortus $45 / 20$. La cepa $45 / 20$ es una cepa rugosa, fue desarrollada por 20 pasajes repetidos de
Brucella abortus 45 en cobayos (Corbeil y col 1988). A pesar de que no induce anticuerpos contra la cadena $\mathrm{O}$ del LPS e induce una protección significativa contra la infección por Brucella abortus (WHO 1997), no es muy utilizada porque es inestable y puede revertir a su forma virulenta in vivo (Corbeil y col 1988). La cepa 45/20 también ha sido utilizada en forma inactiva, pero adicionada junto a un adyuvante oleoso, la que ha demostrado una relativa efectividad, pero provoca una reacción inflamatoria local en el sitio de la inyección (McDonel 1990).

6.1.3. Brucella abortus RB51. Brucella abortus RB51 es una cepa rugosa, resistente a rifampicina, que ha sido derivada de la cepa virulenta Brucella abortus 2308 (Schurig y col 1991, Schurig y col 2002). Esta cepa es utilizada desde 1996 contra la brucelosis bovina en Estados Unidos y en otros países, como Chile. Es administrada en dosis que fluctúan entre $1 \times 10^{10}$ y $4 \times 10^{10}$ UFC por mililitro (Unidades Formadoras de Colonias) en bovinos no menores de 4 meses de edad (Olsen 2000, Vemulapalli y col 2000a). La protección que proporciona la vacunación con esta cepa se debe a la activación de linfocitos T (Stevens y Olsen 1996, Vemulapalli y col $2000^{a}$, Olsen 2000). La vacunación induce altos niveles de IFN- $\gamma$, lo cual es fundamental en las etapas primarias de la infección (Pasquali y col 2001). La inoculación intraperitoneal de $B$. abortus RB51 en ratones resulta en una colonización del bazo que desaparece luego de cuatro semanas postinmunización (Schurig y col 1991). La vacunación del ganado permite la diferenciación entre bovinos vacunados y aquellos infectados con cepas silvestres debido a que no induce anticuerpos contra la cadena O del lipopolisacárido (Pasquali y col 2001). Sin embargo, se ha determinado que puede causar placentitis, endometritis e infección fetal, en vaquillas adultas que han sido vacunadas durante la preñez (Lopetegui 1998, Van Metre y col 1999, Olsen, 2000).

Basándose en reportes sobre la efectividad de la proteína SOD $\mathrm{Cu} / \mathrm{Zn}$ de $B$. abortus expresada en $E$. coli $\mathrm{DH} 5 \alpha$ en proteger a ratones vacunados del desafío con la cepa patogénica de B. abortus 2308 (Oñate y col 1999), Schurig y col desarrollaron una nueva cepa de B. abortus RB51, que sobreexpresa la proteína $\mathrm{SOD} \mathrm{Cu} / \mathrm{Zn}$ de Brucella (B. abortus RB51-SOD) (Vemulapalli y col 2002). La inmunidad protectora proporcionada por la cepa B. abortus RB51-SOD contra Brucella es superior a la de B. abortus RB51, cepa parental, sin alterar las características de atenuación de la vacuna (Vemulapalli y col 2000c).

6.2. Vacunas subcelulares. Se han probado distintos antígenos de Brucella en su capacidad de inducir respuesta inmune mediada por células. Estos antígenos forman parte de la estructura de la bacteria, como la lipoproteína de $18 \mathrm{kDa}$ presente en la superficie de Brucella (Vemulapalli y col 2000b), la proteína 
periplásmica $\mathrm{P} 39$, la proteína bacterioferritina (Al-Mariri y col 2001b) y la proteína ribosomal L7/L12, que produce una protección equivalente a la alcanzada con la cepa 19 de B. abortus en ratones, con activación de células T $\mathrm{CD}^{+}$que secretan niveles significativos de IFN- $\gamma$ (Oliveira y col 1994, Oliveira y col 2002, Ko y Splitter 2003). Las proteínas bacterioferritina y P39 no producen niveles significativos de protección contra Brucella, aunque se utilicen adyuvantes como $\mathrm{CpG}$ en su administración (Al-Mariri y col 2001a). También se han probado proteínas de choque térmico, como las proteínas UvrA, GroEL, GroES y HtrA de B. abortus (Oliveira y col 1996), ya que se ha encontrado que éstas son altamente inmunogénicas en el curso de la infección con Brucella, estimulando tanto la inmunidad celular como la inmunidad humoral en el huésped infectado (Roop II y col 1994); sin embargo, no son capaces de estimular una respuesta inmune protectora eficiente frente a la infección con Brucella (Bae y col 2002). A partir del extracto de proteínas totales de B. abortus RB51 se purificaron dos proteínas: una de 22,9 y otra de 32,2 kDa, de las cuales sólo la proteína de $22,9 \mathrm{kDa}$ demostró ser capaz de otorgar cierto grado de protección (Céspedes y col 2000). Los mejores resultados se han obtenido con la proteína de 18,5 kDa, SOD Cu/Zn de B. abortus, que es capaz de inducir una respuesta celular de tipo Th1, con inducción de la producción de IFN- $\gamma$ e IL-2, pero no de IL-4 (Oñate y Folch 1995) y además la capacidad de inducir una respuesta inmune protectora (Oñate y col 1999).

7. NUEVAS TENDENCIAS EN LA GENERACION DE VACUNAS PARA BRUCELLA. En los últimos años han surgido dos nuevas estrategias de inmunización altamente efectivas, basadas en la vacunación con moléculas de ácidos nucleicos, generándose la aparición de las vacunas de tercera generación, que son las vacunas $\mathrm{ADN}$ y las ARN, aplicándose este tipo de estrategia para la infección por Brucella.

7.1. Vacunas ADN. La inmunización con vectores de expresión plasmidial se basa en la expresión in vivo de algún antígeno seleccionado, que induciría una respuesta inmune protectora, y tienen algunas de las ventajas que presenta el uso de los patógenos vivos o atenuados, pero sin el riesgo de la infección (Tang y col 1992). En principio, el método de vacunación con ácidos nucleicos se basa en el uso de un plásmido bacteriano que tiene un promotor viral fuerte capaz de expresarse en células eucariontes, un gen que codifica para un antígeno seleccionado y una secuencia de término de la transcripción o poliadenilación. El plásmido se replica en una bacteria (E. coli), se purifica y luego se inyecta por una vía determinada en el huésped. Las células del huésped son capaces de sintetizar, procesar y presentar el antígeno a los linfocitos, originando eventualmente una respuesta de células $\mathrm{T}$ y $\mathrm{B}$ específicas para el antígeno seleccionado.
El plásmido es fabricado sin su origen de replicación funcional en células eucariontes, por lo tanto nunca se replica en una célula huésped de mamífero, ni se integra al ADN cromosomal del hospedador (Donnelly y col 1997).

7.1.1. Mecanismos celulares de captura de ADN. Un paso crucial en el desarrollo de la terapia génica por medio de la inyección de ADN desnudo, es la translocación del ADN a través de la membrana plasmática, esto es importante para determinar el mecanismo real de captura de ADN desnudo por células en tejido animal (Satkauskas y col 2001). Estudios en el sitio de inyección con heparina, una molécula policatiónica que inhibe la captación de $\mathrm{ADN}$, indican que la inhibición es dosis dependiente y compatible con la unión al receptor o al sitio de unión específico, asumiendo que el mecanismo de captación de ADN plasmidial es la endocitosis mediada por receptores (Satkauskas y col., 2001). Sin embargo, los últimos estudios en keratinocitos humanos muestran que el mecanismo de captación de ADN es a través de diferentes vías, principalmente por macropinocitosis, y se han identificado las proteínas CD44 e ICAM-1 involucradas en la unión y el tráfico de ADN (Basner-Tschakarjan y col 2004).

\subsubsection{Mecanismos celulares involucrados en la respuesta} inmune generada por la inmunización genética. Algunas de las cualidades de las vacunas ADN son: expresar antígenos de proteínas nativas in vivo para reconocimiento de células B y presentación por moléculas MHC clase I y II para estimular células $\mathrm{T}$ ayudadoras, linfocitos $\mathrm{T}$ citotóxicos. Así, el modo preciso de estimulación inmune de las vacunas ADN se reduce a una combinación de tres mecanismos por los que las proteínas codificadas por el ADN plasmidial son presentadas y procesadas para generar respuesta inmune: a) estimulación directa por células somáticas (miocitos, keratinocitos, o cualquier célula MHC clase II negativa), b) transfección directa de células presentadoras de antígeno (CPA) profesionales (Ej. células dendríticas) y c) presentación cruzada (crosspriming) en la cual el plásmido ADN transfecta una célula somática y/o CPA profesional y la proteína secretada es tomada por otra célula CPA profesional y presentada a células T (Donnelly y col 2000, Gurunathan y col 2000).

7.1.3. Vacunas ADN para B. abortus. Se ha demostrado que vacunas $\mathrm{ADN}$ que contienen el gen para la proteína L7/L12 (Kurar y Splitter 1997) y lumazina sintetasa (Velikovsky y col 2002) inducen un significativo nivel de protección contra brucelosis en el modelo ratón. Por otro lado, ratones $\mathrm{BALB} / \mathrm{c}$ vacunados con un plásmido $\mathrm{ADN}$ que tiene el gen $(\operatorname{sod} C)$ que codifica para la proteína SOD Cu/Zn de Brucella abortus (pcDNA-SOD), desarrollan anticuerpos específicos contra la proteína SOD recombinante (SODr), exhibiendo una dominancia de inmunoglobulinas de tipo IgG2a sobre IgG1, lo que in- 
duce una respuesta proliferativa por parte de células $T$, con la producción INF- $\gamma$ pero no de IL-10 o IL-4, demostrando de esta forma que la inoculación con pcDNASOD induce los anticuerpos adecuados y una respuesta inmune celular de tipo Th1, respuesta que es protectora frente al desafío con la cepa patógena de Brucella (Oñate y col 2003). Además, se ha demostrado en el modelo murino que la inmunización intraesplénica con pcDNASOD induce una eficiente respuesta inmune tipo Th1 protectora y que la producción de IFN- $\gamma$ es realizada por células $\mathrm{T} \mathrm{CD}^{+}$y la inducción de actividad citotóxica, importante para la eliminación de bacterias facultativamente intracelulares como Brucella, es realizada por las células T CD8 (Muñoz y col 2004).

En bovinos, actualmente el único trabajo que ha estudiado la utilización de una vacuna ADN para Brucella describe que la inmunización con pcDNA-SOD es capaz de estimular una respuesta inmune celular y una eficiente estimulación de células T citotóxicas, respuestas clave en la inducción de protección frente a Brucella. Lo que además destaca el trabajo, es la gran variabilidad de respuesta observada en el ganado bovino, lo que podría atribuirse a la constitución genética de la especie bovina con la cual se trabajó, especies que no son $100 \%$ genéticamente puras (Guzmán y col 2004).

7.2. Vacunas ARN. Además de los vectores plasmidiales existen otros vectores de expresión como los basados en el virus Semliki Forest (SFV). Estos vectores son partículas virales suicidas del virus Semliki Forest, cuyo genoma corresponde a un ARN desnudo autorreplicable, cuya secuencia contiene inserto el gen de interés que codifica para la proteína con capacidad inmune. Experimentos previos han demostrado la alta eficiencia de estos sistemas de expresión para expresar proteínas heterólogas en células eucariotas, así como también la capacidad para conferir excelentes niveles de protección en animales inmunizados con estos sistemas de expresión, superando incluso a las vacunas ADN (Andersson y col 2001, Fleeton y col 1999).

7.2.1. Virus Semliki Forest. El virus Semliki Forest es un Alfavirus que pertenece a la familia Togaviridae. Este virus se transmite principalmente a través de mosquitos y es capaz de infectar al ser humano causándole fiebre, artritis y encefalitis (Willems y col 1979.). El virus Semliki Forest es un virus ARN que puede infectar una gran variedad de hospedadores y se replica de manera efectiva en células en cultivo. Este virus se ha utilizado en el estudio de la biología molecular de los virus ARN y además se ha investigado su uso como instrumento en la expresión de proteínas recombinantes (Olkkonen y col 1993, Lundström y col 1994).

7.2.2. Entrada del virus a la célula hospedadora. El virus Semliki Forest entra a la célula hospedadora por endocitosis mediada por receptores (probablemente antígenos de histocompatibilidad), que fijan la partícula viral a la membrana plasmática (Helenius y col 1978); estos receptores se concentran principalmente en invaginaciones de la membrana plasmática, recubiertas en su cara citosólica por una red de la proteína clatrina (DeTulleo y Kirchhausen 1998). En el citoplasma, la vesícula endocítica se fusiona con un endosoma, dentro del cual el pH es ácido, lo cual induce la disociación de la proteína estructural del virus E1E2, lo cual genera la formación del homotrímero E1E1E1, el que facilita la fusión de la membrana viral con el endosoma, liberándose la nucleocápside al citoplasma de la célula. Finalmente, las proteínas de la cápside liberan el genoma viral, mediante una reacción gatillada por ribosomas que se unen a algunos aminoácidos de esta proteína (residuos 94 al 106), los cuales están directamente implicados en la unión de la cápside con la molécula de ARN (Singh y Helenius 1992).

7.2.3. Elaboración de partículas virales suicidas del virus Semliki Forest. A partir del virus Semliki Forest, Smerdou y Liljeström el año 1999 elaboraron una partícula viral recombinante que tiene la capacidad de infectar una célula eucariota animal y liberar su genoma en su interior. Esta partícula viral contiene en su interior un segmento de ARN mensajero, el cual puede ser traducido por la célula hospedera (Smerdou y Liljeström 1999). Para la construcción del virus se separó su genoma en tres plásmidos (pSFV4.2, pSFV-Helper-Capsid y pSFVHelper-Spike), plásmidos que son transcritos in vitro (transcrito ARNm), utilizándolos luego para transfectar una línea celular eucariota, obteniendo de esta forma partículas virales que son empaquetadas y liberadas al medio de cultivo. Durante el proceso de elaboración de las partículas virales in vitro, sólo el ARNm transcrito a partir del plásmido pSFV4.2 contiene la información necesaria para ser empaquetado al interior de la partícula viral, por ende, sólo éste ARNm formará parte del genoma viral (Smerdou y Liljeström 1999). El plásmido que codifica este transcrito contiene un gen que codifica para la replicasa viral y un sitio de multiclonaje, en el cual se puede insertar un gen que codifique una proteína heteróloga (Frolov y col 1996). Estas características le confieren una alta bioseguridad al sistema, debido a que permiten elaborar partículas virales con un genoma incompleto, el cual no puede replicarse (partículas virales suicidas), funcionando como un simple pero eficiente vector de expresión de proteínas heterólogas (Smerdou y Liljeström 1999).

7.2.4. Vacunas ARN para B. abortus. Se ha evaluado en un modelo murino la inducción de respuesta inmune y protección, por un ARN recombinante que codifica la proteína $\mathrm{SOD} \mathrm{Cu} / \mathrm{Zn}$ de $B$. abortus empaquetado en el interior de partículas suicidas del virus Semliki Forest 
(VSF-SOD). Describiéndose que la inmunización con VSF-SOD estimula preferentemente una respuesta inmune de tipo Th1, con la inducción de proliferación de linfocitos $\mathrm{T}$ antígeno específica y activación de células $\mathrm{T}$ citotóxicas. Respuesta que fue protectora frente al desafío con una cepa patógena, indicándose su potencial uso como vacuna para Brucella (Oñate y col 2005).

\section{CONCLUSIONES}

1. Brucelosis es una zoonosis que no ha podido ser erradicada en la gran mayoría de los países, a pesar de la aplicación de agresivos programas de vacunación con vacunas basadas en bacterias vivas atenuadas.

2. Debido al potencial epidémico de Brucella y la eficiencia de la infección por aerosoles, este patógeno es considerado un agente potencial que puede ser utilizado como arma biológica liberado en bombas o a la forma de aerosoles secos.

3. La citotoxicidad es crucial en la erradicación de bacterias intracelulares. Linfocitos $\mathrm{T} \mathrm{CD}^{+}$pueden actuar como células efectoras y eliminar células infectadas con Brucella directamente lisándolas, por esto es fundamental determinar la especificidad de clones de linfocitos TCD $8^{+}$útiles en la protección frente a Brucella.

4. Algunas proteínas purificadas de Brucella ofrecen buenos niveles de protección individualmente; posiblemente una vacuna compuesta por varias subunidades de proteínas antigénicas de Brucella proporcionaría una protección superior.

5. La reciente generación de vacunas genéticas basadas en ácidos nucleicos ADN y ARN ofrecerían nuevas oportunidades de llegar a controlar las infecciones intracelulares.

\section{RESUMEN}

Brucelosis, enfermedad causada por la bacteria intracelular facultativa Brucella abortus, es una zoonosis ampliamente distribuida a nivel mundial que afecta principalmente al ganado bovino, causando esterilidad en machos y abortos en hembras en gestación. La resistencia depende del desarrollo de una inmunidad mediada por células, con la participación de células $\mathrm{T} \mathrm{CD} 4^{+}$de tipo Th1, que secreten interferón gama (INF- $\gamma$ ), citosina que estimula la actividad bactericida por macrófagos y la actividad citotóxica de linfocitos $\mathrm{T} \mathrm{CD} 8^{+}$, que son capaces de matar células infectadas con Brucella. Brucella posee como componentes antigénicos importantes el lipopolisacárido (LPS) y las proteínas, entre las que se destaca por su demostrada capacidad inmune la superóxido dismutasa (SOD). La prevención de la diseminación de la brucelosis se fundamenta en el desarrollo de vacunas eficientes contra $B$. abortus, utilizándose cepas atenuadas de Brucella abortus como la cepa 19 , cepa $45 / 20$ y la cepa RB51; vacunas subcelulares en base a antígenos que forman parte de la estructura de la bacteria y vacunas basadas en moléculas de ácidos nucleicos, como las vacunas $\mathrm{ADN}$ y las vacunas ARN. En la presente revisión se pretende dar una visión actualizada sobre la brucelosis, su patogenia y cuadro clínico. Se hace un análisis de las características genéticas, antigénicas e inmunológicas de Brucella. Luego, una exposición de las vacunas actualmente en uso para su prevención y los estudios con vacunas subcelulares para finalizar con las nuevas tendencias en la generación de vacunas, como las vacunas ADN y ARN para Brucella.

\section{REFERENCIAS}

Allardent-Servent A, G Bourg, M Ramuz, M Pages, M Bellis, G Roizes. 1988. DNA polymorphism in strains of the genus Brucella. J Bacteriol 170, 4603-4607.

Allen C, L Adams, T Fitch. 1998. Transposon-derived Brucella abortus rough mutants are attenuated and exhibit reduced intracelular survival. Infect Immun 66, 1008-1016.

Al-Mariri A, A Tibor, P Mertens, X de Bolle, P Michel, J Godfroid, K Walravens, J Letesson. 2001 ${ }^{\mathrm{a}}$. Protection of BALB/c mice against Brucella abortus 544 challenge by vaccination with bacterioferritin or P39 recombinant proteins with $\mathrm{CpG}$ oligodeoxynucleotides as adjuvant. Infect Immun 69, 4816-4822.

Al-Mariri A, A Tibor, P Mertens, X de Bolle, P Michel, J Godfroid, K Walravens, J Letesson. 2001 ${ }^{\mathrm{b}}$. Induction of immune response in BALB/c mice with a DNA vaccine encoding bacterioferritin or P39 of Brucella spp. Infect Immun 69, 6264-6270.

Andersson C, N Vasconcelos, M Sievertzon, D Haddad, S Liljeqvist, P Berglund, P Liljeström, N Ahlborg, S Stahl, K Berzins. 2001. Comparative immunization study using RNA and DNA constructs encoding a part of the Plasmodium falciparum antigen Pf332. Scand J Immunol $54,117-24$.

Aréstegui M, C Gualtieri, J Domínguez, G Scharovsky. 2001. El género Brucella y su interacción con el sistema mononuclear fagocítico. Vet Méx 32, 131-139.

Bae J. 1999. Generation of baculovirus-Brucella abortus heat shock protein recombinants; mice immune responses against the recombinants, and B. abortus superoxide dismutase and L7/L12 recombinant proteins. Ph.D thesis. Virginia Polytechnic Institute and State University, Blacksburg, Virginia, USA.

Bae J, G Schuring, T Toth. 2002. Mice immune responses to Brucella abortus heat shock proteins use of vaculovirus recombinant-expressing whole insects cells, purified Brucella abortus recombinant proteins, and a vaccinia virus recombinant as immunogens. Vet Microbiol 88, 189202.

Baldwin C, T Sathiyaseelan, B Naiman, A White, R Brown, S Blumerman, A Rogers, S Black. 2002. Activation of bovine peripheral blood $\gamma \delta \mathrm{T}$ cells for cell division and IFN- $\gamma$ production. Vet Immunol Immunopathol 87, 251259.

Basner-Tschakarjan E, A Mirmohammadsadegh, A Baer, U Hengge. 2004. Uptake and trafficking of DNA in keratinocytes: evidence for DNA-binding proteins. Gene Ther 11, 765-74.

Birmingham J, L Tabatabai, B Deyoe, E Jeska, M Nuessen. 1982. Generation of chemotactic factor for granulocytes and monocytes from serum by fractions of Brucella abortus. Immunology 46, 17-22. 
Briones G, N Iñon de Iannino, M Roset, A Vigliocco, P Silva, R Ugalde. 2001. Brucella abortus cyclic $\beta$-1,2-glucan mutants have reduced virulence in mice and are defective in intracellular replication in HeLa cells. Infect Immun 69, 4528-4535.

Canning P, J Roth, L Tabatabai, B Deyoe. 1985. Isolation of components of Brucella abortus responsible for inhibition of function in bovine neutrophils. J Infect Dis 152, 913-921.

Caroff M, D Bundle, M Perry, J Cherwonogrodzky, J Duncan. 1984. Antigenic S-type lipopolysaccharide of Brucella abortus 1119-3. Infect Immun 46, 384-388.

Celli J, Ch Chastellier, D Franchini, J Pizarro-Cerda, E: Moreno, J Gorvel. 2003 Brucella evades macrophage killing via VirB-dependent sustained interactions with the endoplasmic reticulum. J Exp Med 198, 545-556.

Céspedes S, E Andrews, H Folch, A Oñate. 2000. Identification and partial characterization of a new protective antigen of Brucella abortus. J Med Microbiol 49, 165-170.

Cloeckaert A, M Grayon, O Grepinet. 2000. An IS711 element downstream of the $b p 26$ gene is a specific marker of Brucella spp. isolated from marine mammals. Clin Diagn Lab Immunol 7, 835-839.

Cloeckaert A, N Vizcaino, J Paquet, R Bowden, P Elzer. 2002. Major outer membrane proteins of Brucella spp.: past, present and future. Vet Microbiol 90, 229-47.

Corbeil L, K Blau, T Inzana, K Nielsen, R Jacobson, R Corbeil, A Winter. 1988. Killing of Brucella abortus by bovine serum. Infect Immun 56, 3251-3261.

Corbel M. 1997. Brucellosis: an overview. Emerg Infect Dis 3, 213-221.

DeTulleo L, T Kirchhausen. 1998. The clathrin endocytic pathway in viral infection. EMBO J 17, 4585-4593.

Dieli F, F Poccia, M Lipp, G Sireci, N Caccamo, C di Sano, A Salerno. 2003. Differentiation of effector/memory V $\delta 2$ $\mathrm{T}$ cells and migratory routes in lymph nodes or inflammatory sites. J Exp Med 198, 391-397.

Donnelly J, J Ulmer, J Shiver, M Liu. 1997. DNA vaccines. Annu Rev Immunol 15, 617-48.

Donnelly J, M Liu, J Ulmer. 2000. Antigen presentation and DNA vaccines. Amer J Resp Crit Care Med 162, 190-193.

Douglas J, E Rosenberg, H Nikaido, D Verstreate, A Winter. 1984. Porins of Brucella species. Infect Immun 44, 16-21.

Eisenschenk F, J Houle, E Hoffmann. 1999. Mechanism of serum resistance among Brucella abortus isolates. Vet Microbiol 68, 235-44.

Elzer P, R Philips, G Robertson, R Roop II. 1996. The HtrA stress response protease contributes to resistance of Brucella abortus to killing by murine phagocytes. Infect Immun 64, 4838-4841.

Fernández D, C Baldwin. 1995. Interleukin-10 downregulates protective immunity to Brucella abortus. Infect Immun 63, 1130-1133.

Fernández D, R Benson, C Baldwin. 1995. Lack of a role for natural killer cells in early control of Brucella abortus 2308 infections in mice Infect Immun 63, 4029-4033.

Fernández-Prada C, M Nikolich, R Vemulapalli, N Sriranganathan, S Boyle, G Schurig, T Hadfield, D Hoover. 2001. Deletion of wboA enhances activation of the lectin pathway of complement in Brucella abortus and Brucella melitensis. Infect Immun 69, 4407-4416.

Ficht T. 2003. Intracellular survival of Brucella: defining the link with persistence. Vet Microbiol 92, 213-223.
Ficht T, S Bearden, B Sowa, G Adams. 1989. DNA sequence and expression of the 36-kilodalton outer membrane protein gene of Brucella abortus. Infect Immun 57, 3281-3291.

Fiori P, S Mastrandrea, P Rappelli, P Cappuccinelli. 2000. Brucella abortus infection acquired in microbiology laboratories. J Clin Microbiol 38, 2005-2006.

Fleeton M, B Sheahan, E Gould,G Atkins, P Liljeström. 1999. Recombinant Semliki Forest virus particles encoding the prME or NS1 proteins of louping ill virus protect mice from lethal challenge. J Gen Virol 80,1189-1198.

Folch H, A Oñate. 1995. Propiedades mitogénicas y caracterización de diferentes fracciones polisacáridas obtenidas de dos especies de Brucella. Arch Med Vet 27, 85-92.

Forestier C, F Deleuil, N Lapaque, E Moreno, J Gorvel. 2000. Brucella abortus lipopolysaccharide in murine peritoneal macrophages acts as a down-regulator of $\mathrm{T}$ cell activation. J Immunol 165, 5202-5210.

Frolov I, T Hoffman, B Pragai, S Dryga, HV Huang, S Schlesinger, CM Rice. 1996. Alphavirus-based expression vectors: strategies and applications. Proc Natl Acad Sci USA 93, 11371-11377

Gándara B, A López, M Rigel, E Martínez-Romero. 2001. Limited genetic diversity of Brucella spp. J Clin Microbiol $39,235-240$.

Giambartolomei G, M Delpino, M Cahanovich, J Wallach, P Balde, C Velikovsky, C Fossati. 2002. Diminished production of $\mathrm{T}$ helper 1 cytoquines correlates with $\mathrm{T}$ cell unresponsiveness to Brucella cytoplasmic proteins in chronic human brucellosis. J Infect Dis 186, 252-259.

Golding B, D Scott, O Scharf, L Huang, M Zaitseva, C Lapham, N Eller, H Golding. 2001. Immunity and protection against Brucella abortus. Microbes Infect 3, 43-48.

Gurunathan S, D Klinman, R Seder. 2000. DNA vaccines: immunology, application, and optimization. Ann Rev Immunol 18, 927-974.

Guzmán I, E Andrews, A González, R Rivers, A Cabrera, A Oñate. 2004. Una vacuna ADN para la brucelosis bovina. Resúmenes del XIII Congreso Chileno de Medicina Veterinaria, Valdivia, pp. 30.

Guzmán-Berri C, E Chaves-Olarte, C von Eichel-Streibe, I López-Goñi, M Thelestam, S Arvidson, J Gorvel, E Moreno. 2001. GTPases of the Rho subfamily are sequired for Brucella abortus internalization in nonprofessional phagocytes. J Biol Chem 276, 44435-44443.

Halling S, B Peterson-Burch, B Bricker, R Zuerner, Z Qing, L Li, V Kapur, D Alt, S Olsen. 2005. Completion of the genome sequence of Brucella abortus and comparison to the highly similar genome of Brucella melitensis and Brucella suis. J Bacteriology 187, 2715-2726.

Hausler W, F Koontz. 1974. Manual of Clinical Microbiology. $2^{\text {nd }}$ ed. E. Lennette, E. Spaulding, J. Truant (eds.). American Society of Microbiology. Washington, D. C. Pgs. 295-301.

Helenius A, B Morein, E Fries, K Simons, P Robinson, V Schirrmacher, C Terhorst, J Strominger. 1978. Human (HLA-A and HLA-B) and murine (H-2K and H-2D) histocompatibility antigens are cell surface receptors for Semliki Forest virus. Proc Nat Acad Sci USA 75, 38463850.

Hinsdill R, D Berman. 1967. Antigens of Brucella abortus I. Chemical and Immunoelectrophoretic Characterization. J Bacteriol 93, 544-549. 
Hong P, R Tsolis, T Ficht. 2000. Identification of genes required for chronic persistence of Brucella abortus in mice. Infect Immun 68, 4102-4107.

Ilarmon B, L Adams, M Frey. 1988. Survival of rough and smooth strains of Brucella abortus in bovine mammary gland macrophages. Am J Vet Res 49, 1092-1097.

Ko J, G Splitter. 2003. Molecular host-pathogen interaction in brucellosis: current understanding and future approaches to vaccine development for mice and humans. Clin Microbiol Rev 16, 65-78.

Kurar E, G Splitter. 1997. Nucleic acid vaccination of Brucella abortus ribosomal L7/L12 gene elicits immune response. Vaccine 15, 1851-1857.

Lopetegui P. 1998. Erradicación de brucellosis bovina en Chile. Experiencia en el uso de la vacuna cepa RB51. En: LunaMartínez E, F Suárez-Guemes (eds). III Foro Nacional de brucelosis, Acapulco. Pp 159-179. Anonymous. México.

Lucero N, L Foglia, S Ayala, D Gall, K Nielsen. 1999. Competitive enzyme immunoassay for diagnosis of human brucellosis. J Clin Microbiol 37, 3245-3248.

Lundström K, A Mills, G Buell, E Allet, N Adami, P Liljeström. 1994. High-level expression of the human neurokinin-1 receptor in mammalian cell lines using the Semliki Forest virus expression system. Eur J Biochem 224, 917-21.

Meyer M. 1964. The epizootiology of brucellosis and its relationship to the identificaction of Brucella organisms. Am J Vet Res 25, 553-557.

Mandell G, J Bennet, R Dolin. 1995. Principles and practice of infectious diseases. $4^{\text {th }}$ ed. Vol 2., Pp. 2053-2057. Churchill Livingstone. Philadelphia, USA.

Meador V, B Deyoe. 1989 Intracellular Localization of Brucella abortus in bovine placenta. Vet Pathol 26, 513-515.

McDonel J. 1990. Brucella vaccines. In, A. Mizrahi, ed. Advances in Biotechnological Processes, Vol 13. Bacterial Vaccines. Pp. 105-122. Wiley-Liss Publishers, New York, NY.

Montaraz J, A Winter, D Hunter, D Sowa, A Wu, L Adams. 1986. Protection against Brucella abortus in mice with Opolysaccharide-specific monoclonal antibodies. Infect Immun 51, 961-963.

Moreno E. 2002. Brucellosis in Central América. Vet Microbiol 90, 31-38.

Moreno E, I Moriyón. 2002. Brucella melitensis: a nasty bug with hidden credentials for virulence. Proc Nat Acad Sci 99, 1-3.

Muñoz-Montesino C, E Andrews, R Rivers, A González-Smith, G Moraga-Cid, H Folch, S Céspedes, A Oñate. 2004. Intraspleen delivery of a DNA vaccine coding for superoxide dismutase (SOD) of Brucella abortus induces SOD-specific $\mathrm{CD}^{+}$and $\mathrm{CD} 8^{+} \mathrm{T}$ cells. Infect Immun 72 , 2081-2087.

Murphy E, G Robertson, M Parent, S Hagius, R Roop II, P Elzer, C Baldwin. 2002. Major histocompatibility complex class I and II expression on macrophages containing a virulent strain of Brucella abortus measured using green fluorescent protein-expressing brucellae and flow cytometry. FEMS Immunol Med Microbiol 33, 191-200.

Oliveira S, Y Zhu, G Splitter. 1994. Recombinant L7/L12 ribosomal protein and gamma-irradiated Brucella abortus induce a T-helper 1 subset response from murine $\mathrm{CD} 4^{+} \mathrm{T}$ cells. Immunology 83, 659-664.
Oliveira S, G Splitter. 1996. Immunization of mice with recombinant $\mathrm{L} 7 / \mathrm{L} 12$ ribosomal protein confers protection against Brucella abortus infection. Vaccine 14, 959-962.

Oliveira S, J Harms, M Banai, G Splitter. 1996. Recombinant Brucella abortus proteins that induce proliferation and gamma-interferon secretion by $\mathrm{CD} 4^{+} \mathrm{T}$ cells from Brucellavaccinated mice and delayed-type hypersensitivity in sensitized guinea pigs. Cell Immunol 172, 262-268.

Oliveira S, N Soeurt, G Splitter. 2002. Molecular and cellular interactions between Brucella abortus antigens and host immune responses. Vet Microbiol 90, 417-424.

Olkkonen V, P Liljeström, H Garoff, K Simons, C Dotti. 1993. Expression of heterologous proteins in cultured rat hippocampal neurons using the Semliki Forest virus vector. J Neurosci Res 35, 445-51.

Olsen S. 2000. Responses of adult cattle to vaccination with a reduced dose of Brucella abortus strain RB51. Res Vet Sci $69,135-140$.

Oñate A, H Folch. 1995. Proteína de 18.5 kDa: un antígeno interesante en Brucella. Arch Med Vet 27, 93-102.

Oñate A, R Vemulapalli, E Andrews, G Schurig, S Boyle, H Folch. 1999. Vaccination with live Escherichia coli expressing Brucella abortus $\mathrm{Cu} / \mathrm{Zn}$ superoxide dismutase protects mice against virulent $B$. abortus. Infect Immun 67 , 986-988.

Oñate A, E Andrews, A Beltran, G Eller, G Schurig, H Folch. 2000. Frequent exposure of mice to crude Brucella abortus proteins down-regulates immune response. J Vet Med 47, 677-682.

Oñate A, S Céspedes, A Cabrera, R Rivers, A González, C Muñoz, H Folch, E Andrews. 2003. A DNA vaccine encoding $\mathrm{Cu} / \mathrm{Zn}$ superoxide dismutase of Brucella abortus induces protective immunity in $\mathrm{BALB} / \mathrm{c}$ mice. Infect Immun $71,4857-4861$

Oñate A, G Donoso, G Moraga-Cid, H Folch, S Céspedes, E Andrews. 2005. A RNA Vaccine Based on Recombinant Semliki Forest Virus Particles Expressing $\mathrm{Cu} / \mathrm{Zn}$ Superoxide Dismutase Protein of Brucella abortus Induces Protective immunity in BALB/c Mice. Infect Immun 73, 3294-3300

Pasquali P, R Adone, L Gasbarre, C Pistoia, F Ciuchini. 2001. Mouse cytokine profiles associated with Brucella abortus RB51 vaccination or B. abortus 2308 infection. Infect Immun 69, 6541-6544.

Pasquali P, R Adone, L Gasbarre, C Pistoia, F Ciuchini. 2002. Effect of exogenous interleukin-18 (IL-18) and IL-12 in the course of brucella abortus 2308 infection in mice. Clin Diagn Lab Immunol 9, 491-492.

Pizarro-Cerda J, S Merece, R Parton, G van Der-Goot, A SolaLanda, I Lopez-Goñi, E Moreno, J Gorvel. 1998. Brucella abortus transits through the autophagic pathway and replicates in the endoplasmic reticulum of nonprofessional phagocytes. Infect Immun 66, 5711-5724.

Pontow S, V Kery, D Stahl. 1992. Mannose receptor. Int Rev Cytol 139, 221-224.

Ramírez M, J Sigal. 2002. Macrophages and Dendritic Cells use the cytosolic pathway to rapidly Cross-Present antigen from live, vaccinia-infected cells. J Immunol 169, 6733-6742.

Rivera S, M Ramírez, I Lopetegui. 2002. Eradication of bovine brucellosis in the 10th Region de Los Lagos, Chile. Vet Microbiol 90, 45-53. 
Rodríguez A, A Orduña, X Ariza, I Moriyon, R Díaz, J Blasco, A Almaraz, F Martínez, C Ruiz, R Abad. 2001. Manual de Brucelosis. Ed. Junta de Castilla y León. Copyright. Zamora, España.

Roop II R, T Fletcher, N Sriranganathan, S Boyle, G Schurig. 1994. Identification of an immunoreactive Brucella abortus HtrA stress response protein homolog. Infect Immun 62, 1000-1007.

Santos J, D Verstreate, V Perera, A Winter. 1984. Outer membrane proteins from rough strains of four Brucella species. Infect Immun 46, 188-194.

Satkauskas S, M Bureau, A Mahfoudi, L Mir. 2001. Slow accumulation of plasmid in muscle cells: supporting evidence for a mechanism of DNA uptake by receptormediated endocytosis. Mol Ther 4, 317-323.

Sauret J, N Vilissova. 2002. Human Brucellosis. J. Am Board Fam Pract 15, 401-406.

Scharf O, I Agranovich, K Lee, N Eller, L Levy, J Inman, D Scott, B Golding. 2001. Ontogeny of Th1 memory responses against a Brucella abortus conjugate. Infect Immun 69, 5417-5422.

Schurig G, R Roop II, T Bagchi, S Boyle, D Buhrman, N Sriranganathan. 1991. Biological properties of RB51: a stable rough strain of Brucella abortus. Vet Microbiol 28, 171-188.

Schurig G, N Sriranganathan, M Corbel. 2002. Brucellosis vaccines: past, present and future. Vet Microbiol 90, 479496.

Singh I, A Helenius. 1992. Role of ribosomes in Semliki Forest virus nucleocapsid uncoating. $J$ Virol 66, 7049-7058.

Smerdou C, P Liljeström. 1999. Two-helper RNA system for production of recombinant Semliki Forest virus particles. J Virol 73, 1092-1098.

Smith H, R Fritzgeorge. The chemical basis of the virulence of Brucella abortus. V. 1964. The basis of intracellular survival and growth in bovine phagocytosis. Brit J Exp Path $45,174-186$

Splitter G, S Oliveira, M Carey, C Miller, J Ko, J Covert. 1996. $\mathrm{T}$ lymphocyte mediated protection against facultative intracellular bacteria. Vet Immunol Immunopathol 54, 309319.

Stevens M, S Olsen, G Pugh. 1994. Lymphocyte proliferation in response to Brucella abortus 2308 or RB51 antigens in mice infected with strain 2308, RB51, or 19. Infect Immun 62, 4659-4663.

Stevens M, S Olsen. 1996. Antibody responses to Brucella abortus 2308 in cattle vaccinated with B. abortus RB51. Infect Immun 64, 1030-1034.

Tabatabai L, S Hennager. 1994. Cattle serologically positive for Brucella abortus have antibodies to B. abortus $\mathrm{Cu}-\mathrm{Zn}$ superoxide dismutase. Clin Diagn Lab Immunol 1, 506510.

Tang D, M Devit, S Johnston. 1992. Genetic immunization is a simple method for eliciting an immune response. Nature $356,152-4$.

Van Metre D, G Kennedy, S Olsen, G Hansen, D Ewalt. 1999. Brucellosis induced by RB51 vaccine in a pregnant heifer. $J$ Am Vet Med Assoc 215, 1491-1493.

Vasselon T, P Detmers. 2002. Toll receptors: a central element in innate immune responses. Infect Immun 70, 1033-1041.

Velikovsky C, J Cassataro, G Giambartolomei, F Goldbaum,
S Estein, R Bowden, L Bruno, C Ffossati, M Spitz. 2002. A DNA vaccine encoding lumazine synthase from Brucella abortus induces protective immunity in $\mathrm{BALB} / \mathrm{c}$ mice. Infect Immun 70, 2507-11.

Vemulapalli R, Y He, L Buccolo, S Boyle, N Sriranganathan, G Schurig. 2000a. Complementation of Brucella abortus RB51 with a functional $w b o A$ gene results in $\mathrm{O}$-antigen synthesis and enhanced vaccine efficacy but no change rough phenotype and attenuation. Infect Immun 68, 39273932.

Vemulapalli R, S Cravero, C Calvert, T Toth, N Sriranganathan, S Boyle, O Rosseti, G Schurig. 2000b. Characterization of specific immune responses of mice inoculated with recombinant vaccinia virus expressing an 18-kilodalton outer membrane protein of Brucella abortus. Clin Diagn Lab Immunol 7, 114-118.

Vemulapalli R, Y He, S Cravero, N Sriranganathan, S Boyle, G Schurig. 2000c. Overexpression of protective antigen as a novel approach to enhance vaccine efficacy of Brucella abortus strain RB51. Infect Immun 68, 3286-3289.

Vemulapalli R, Y He, N Sriranganathan, S Boyle, G Schurig. 2002. Brucella abortus RB51: enhancing vaccine efficacy and developing multivalent vaccines. Vet Microbiol 90, 521-532.

Verger J, F Grimont, P Grimont, M. Grayon. 1985. Brucella a monospecific genus as shown by deoxyribonucleic acid hybridization. Int J Syst Bacteriol 35, 292-295.

Verstreate D, M Creasy, N Caveney, C Baldwin, M Blab, A Winter. 1982. Outer membrane proteins of Brucella abortus: isolation and characterization. Infect Immun 35, 979-989.

Verstreate D, A Winter. 1984. Comparison of sodium dodecyl sulfate-polyacrylamide gel electrophoresis profiles and antigenic relatedness among outer membrane proteins of 49 Brucella abortus strains. Infect Immun 46, 182-187.

WHO. The Development of New/Improved Brucellosis Vaccines: Report of WHO Meeting with the participation of the Food and Agricultural Organization of the United Nations (FAO) and the Office International des Epizooties (OIE). World Health Organization. Geneva, Switzerland 11-12 December 1997.

Wilkinson P. 1980. Leukocyte locomotion and chemotaxis: effects of bacteria and viruses. Rev Infect Dis 2, 293-318.

Willems W, G Kaluza, C Boschek, H Bauer, H Hager, H Schutz, H Feistner. 1979. Semliki forest virus: cause of a fatal case of human encephalitis. Science 203, 1127-1129.

Wyckoff III J. 2002. Bovine T lymphocyte responses to Brucella abortus. Vet Microbiol 90, 395-415.

Yagupsky P. 1999. Detection of Brucellae in blood cultures. $J$ Clin Microbiol 37, 3437-3442.

Young E, J Borchert, F Kreutzer, D Musher. 1985. Phagocytosis and killing of Brucella by human polymorphonuclear leukocytes. J Infect Dis 151, 682-690.

Zhan Y, A Kelso, C Cheers. 1995. Differential activation of Brucella-reactive $\mathrm{CD}^{+} \mathrm{T}$ cells by Brucella infection or immunization with antigenis extracts. Infect Immun 63, 969-975.

Zhan Y, Z Liu, C Cheers. 1996. Tumor necrosis factor alpha and interleukin-12 contribute to resistance to the intracellular bacterium Brucella abortus by different mechanisms. Infect Immun 64, 2782-2786. 